\title{
Numerical and experimental investigations for distortion-reduced laser heat treatment of aluminum
}

\author{
Nikolaos Rigas $^{1}$ (I) $\cdot$ Marion Merklein ${ }^{1}$
}

Received: 19 January 2021 / Accepted: 4 February 2021 / Published online: 10 March 2021

(c) The Author(s) 2021

\begin{abstract}
In the field of mobility, increased safety and emission requirements lead to steadily rising demands on materials used and their performance. Over the last decades, 5000 and 6000 series aluminum alloys have become more and more attractive as lightweight material due to their beneficial weight to strength ratio. The 7000 series offers extended lightweight potential due to its high strength. Until now, this class of alloys has not been widely used in mass production due to its limited corrosion resistance and poor forming behavior. By using so-called Tailor Heat Treated Blanks, it is possible to set increased forming limits of previously locally heat treated components. The reason for the enhanced formability is the local softening, with the resulting improved material flow and the reduced critical forming stresses of the sheet metal before the forming operation. Despite these advantages, the use of previously heat treated materials has been very limited so far. For example, the distortion that occurs during local heat treatment reduces geometrical accuracy and thus automated handling. Therefore, the focus of this thesis is the investigation of tailored heat treatment strategies, permitting a distortion-reduced local short-term heat treatment. For this purpose, the distortion behavior is represented and quantified both numerically and experimentally. The generated knowledge is then transferred to a large volume component and characterized.
\end{abstract}

Keywords AA7075 · Tailor Heat Treated Blanks $\cdot$ Distortion $\cdot$ Mechanical properties $\cdot$ Simulation

\section{Introduction}

In recent years, the mobility sector has changed significantly and is undergoing a continuous transformation. For example, social and ecological aspects are getting more into the focus of the automotive industry and require therefore adapted technical solution concepts. In addition to the use of alternative driving concepts free of internal combustion engines, active and passive passenger safety as well as increased recycling and environmental protection are also becoming more important. One opportunity to satisfy these requirements and fulfill the mentioned demands is the reduction of vehicle weight while preserving the necessary comfort and safety needs. New materials and adapted forming methods

Nikolaos Rigas

nikolaos.rigas@fau.de

Marion Merklein

marion.merklein@fau.de

1 Institute of Manufacturing Technology (LFT), FriedrichAlexander-Universität Erlangen-Nürnberg, Egerlandstraße 11 - 13, 91058 Erlangen, Germany offer promising possibilities to realize these demands. The use of high-strength aluminum alloys provides the chance to replace crash-relevant steel components by light aluminum components and thereby significantly reduce the vehicle weight. Currently, the use of these materials in automotive engineering is still limited due to the limited forming potential. By using blanks with tailored properties, it is possible to adjust both the formability as well as the final product parameters. With the help of so-called Tailored Heat Treated Blanks (THTB), the mechanical properties of blanks [1] as well as profiles [2] can be modified by local heat treatment. This allows a selective adjustment of the forming behavior. The most relevant factor, therefore, is the strength distribution of the used blanks. In the forming zones, low flow stresses are aimed to minimize the necessary forming forces for plastification of the material. Hofmann showed that the critical areas of the blank where force is applied and deep drawing is critical, high strength must be set in order to avoid material failure [3]. The combination of softened and non-softened areas reduce the forming forces and increase the formability as well. Investigations of Geiger et al. demonstrate that the local heat treatment of aluminum blanks can 
improve the drawing depth of complex-shaped components by up to $86 \%$ [4].

For the local heat treatment of blanks, different ways of heating exist. The most common methods are heating by induction, heat conduction by using heated contact plates and laser irradiation [5]. Because of the low setup and adjustment effort as well as the localized heating, using lasers for heating has proven to be advantageous, especially for prototype treatment and small series [6]. In order to ensure only a local heat treatment of the components and prevent uncontrolled heating of components by heat flow in unwanted zones, Vogt demonstrated that the shortest possible heating time should be selected [5]. During the local heat treatment of sheets by laser irradiation, thermal stresses occur. These stresses cause plastic deformations wich are responsible for the component distortion [7]. Kahrimanidis et al. proved that this effect can be avoided by using alternative heat treatment strategies such as inductive heating and conductive plate heating and by using suitable clamping devices during the heat treatment and cooling period [8]. Because during laser heat treatment the component is heated optically, clamping of the sheets is not possible.

\subsection{Influence of heat treatment on the geometrical accuracy}

In the past, several studies on laser-assisted sheet metal forming have been carried out to characterize and quantify the occurring mechanism. Vollertsen showed that laser beam heating can be used to form components in a targeted area and explains the mechanisms and influences on the resulting geometric component changes [7]. In general, it can be assumed that reversible elastic shape changes occur during laser beam heating as long as the irradiation temperature is below the limit temperature $\mathrm{T}_{\mathrm{G}}$. As soon as the materialspecific limit temperature is exceeded and there is no longer a purely elastic deformation, irreversible plastic deformation occurs as well. The limit temperature $\mathrm{T}_{\mathrm{G}}$ necessary to achieve a plastic deformation depends on the correlation of thermal strain and the mechanical material properties [9].

$T_{G}=\frac{k_{f}}{a_{t h} * E}$

The most common dimensional changes can be explained by four thermal mechanisms. On the one hand, the mechanisms are caused by a temperature gradient in the direction of sheet thickness and are divided into the temperature gradient mechanism (TGM) and the residual stress relaxation mechanism (RSRM) [10]. On the other hand, there is the buckling mechanism (BM) and the upsetting mechanism (UM), which are characterized by homogeneous heating over the entire material cross-section. The residual stress relaxation mechanism (RSRM) is regarding the thermal deformation principle similar to the TGM, but for localized energy input and no linear energy input. The irradiation strategies used have an influence on the occurring temperature gradient and thus on the geometrical changes of the sheet material. During continuous irradiation, the temperature gradient mechanism, the buckling mechanism and the upsetting mechanism can occur [11]. For spotwise component heat treatment, the residual stress relaxation mechanism, as well as the temperature gradient mechanism, can appear [7]. In Fig. 1 the different distortion mechanisms and their thermal

\begin{tabular}{|c|c|c|c|c|}
\hline Mechanism & Isothermal curve & $\begin{array}{l}\text { Thermal } \\
\text { deformation }\end{array}$ & $\begin{array}{l}\text { Resulting } \\
\text { deformation }\end{array}$ & Numerical description \\
\hline $\begin{array}{l}\text { Temperature } \\
\text { Gradient } \\
\text { Mechanism (TGM) } \\
{[13]}\end{array}$ & & & & $\alpha_{\mathrm{B}}=3 \frac{\alpha_{\mathrm{th}}}{\rho \mathrm{c}_{\mathrm{p}}} \frac{P_{1} A}{v} \frac{1}{s_{0}{ }^{2}}$ \\
\hline $\begin{array}{l}\text { Buckling } \\
\text { Mechanism (BM) } \\
\text { [7] }\end{array}$ & $\square$ & $\prod \underbrace{\varepsilon_{h}}_{t h}$ & & $\alpha_{\mathrm{B}}=\left(\frac{36 \alpha_{\mathrm{th}} k_{f}\left(T_{1}\right) A p l}{c_{p} \rho E v{s_{0}}^{2}}\right)^{\frac{1}{3}}$ \\
\hline $\begin{array}{l}\text { Upsetting } \\
\text { Mechanism (UM) } \\
{[7]}\end{array}$ & & th $\leftrightarrow \varepsilon_{p l}$ & & $\alpha_{\mathrm{B}}=\frac{1}{b}\left(\frac{2 \alpha_{\mathrm{th}} A p_{l} b}{v_{l} c_{p\left(2 d l s_{0}-s_{\left.0^{2}\right) \rho}\right.}}-\frac{k_{f}\left(T_{1}\right) d_{l}}{E\left(T_{1}\right)}\right)$ \\
\hline $\begin{array}{l}\text { Residual Stress } \\
\text { Relaxation } \\
\text { Mechanism } \\
\text { (RSRM) [7] }\end{array}$ & Start of irradiation & End of irradiation & Final condition & $\alpha_{\mathrm{B}}=\frac{\sigma_{r} d_{l}}{E s_{0}}$ \\
\hline
\end{tabular}

Fig. 1 Overview of the most important distortion mechanisms and their mathematical description [13] 
and geometrical characteristics, as well as the numeric correlation of different influencing variables on the resultant angle of bend $\alpha_{\mathrm{B}}[\mathrm{rad}]$, are illustrated. These are dependent from $\alpha_{\mathrm{th}}=$ coefficient of thermal expansion [10-6/K], $\rho=$ mass density $\left[\mathrm{kg} / \mathrm{m}^{3}\right], \mathrm{c}_{\mathrm{p}}=$ specific heat capacity $[\mathrm{J} / \mathrm{kg} \mathrm{K}]$, $\mathrm{v}=$ velocity $[\mathrm{m} / \mathrm{s}], \mathrm{s}_{0}=$ sheet thickness $[\mathrm{m}], \mathrm{A}=$ absorption coefficient, $\mathrm{P}_{1}=$ laser power [W], $\mathrm{b}=$ breadth of bending angle $[\mathrm{m}], \mathrm{A}_{\mathrm{pl}}=$ absorbed power $[\mathrm{W}], \mathrm{v}_{1}=$ traverse velocity of extrusion relative to laser beam $[\mathrm{m} / \mathrm{s}], \mathrm{d}_{1}=$ laser beam diameter $[\mathrm{m}], \mathrm{k}_{\mathrm{f}}\left(\mathrm{T}_{1}\right)=$ flow stress at temperature $\mathrm{T}_{1}[\mathrm{MPa}]$, $\sigma_{\mathrm{r}}=$ surface tension $[\mathrm{MPa}]$ and $\mathrm{E}\left(\mathrm{T}_{1}\right)=$ elastic modulus at temperature $T_{1}[\mathrm{GPa}][7,9,12]$. Because the resulting distortion angle depends on the applied laser power $\mathrm{P}_{1}$ and the laser velocity $\mathrm{v}$, the duration of irradiation $\mathrm{t}[\mathrm{s}]$ also influences the distortion angle.

In this study, the identification of different irradiation strategies for short-term heat treatment of high-strength aluminum alloys with minimum distortion is aimed. For this purpose, the temperature-dependent material properties of the alloy AA7075 is first examined in Sect. 2. In Sect. 3 the distortion behavior of the material as a function of different irradiation strategies is experimentally and numerically investigated. Subsequently, two different irradiation strategies are transferred to large-volume components in Sect. 4 and the occurring forming properties are examined. Finally, a conclusion is given in Sect. 5 .

\section{Analysis of the temperature dependent material properties}

To be able to reproduce the temperature- and time-dependent material behavior of the aluminum alloy AA7075, the material properties are characterized in advance. For this purpose isothermal tensile tests, hardness measurements and the coefficient of thermal expansion are determined.

\subsection{Mechanical properties of AA7075 after short-time heat treatment}

The used material is the commercially available high strength aluminum alloy AA7075 in the initial condition T6. In order to determine the necessary material temperatures for a sufficient softening and thereby a specific adjustment of the material properties using local laser heat treatment, the material behavior of the alloy AA7075 after previous short-term laser heat treatment is investigated. For this purpose, the material is heated up to different maximum temperatures by using a diode laser type LDM 3000-100 and subsequently characterized through uniaxial tensile tests according to DIN EN ISO 6892-1. In Fig. 2, the material properties of the alloy AA7075 as a function of different heat treatment temperatures are shown. It can

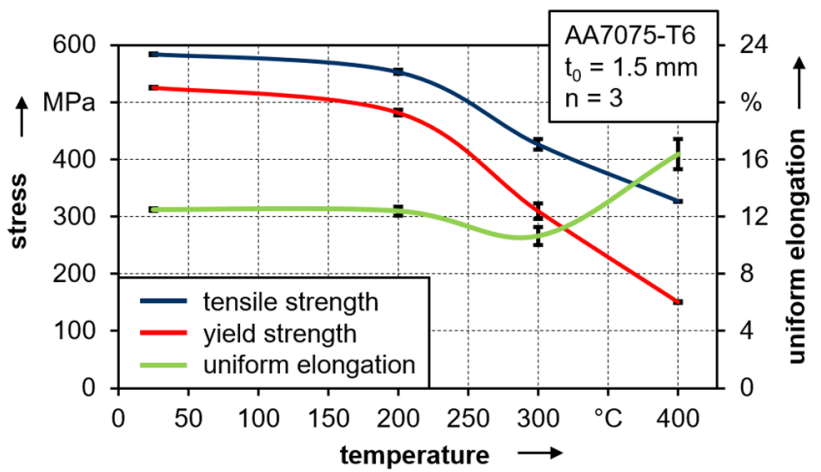

Fig. 2 Mechanical properties of AA7075 after laser heat treatment with laser radiation

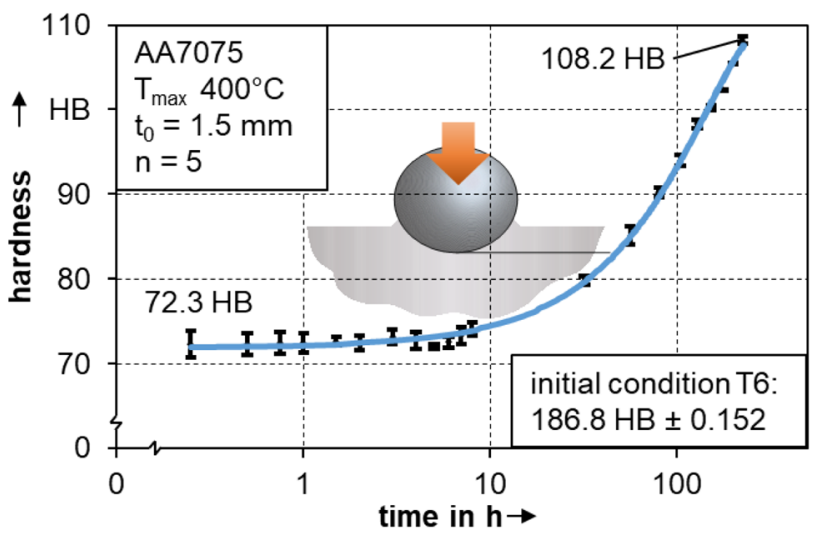

Fig. 3 Hardness distribution of AA7075 after short-time heat treatment of max. $400{ }^{\circ} \mathrm{C}$

be observed that the material exhibits lower tensile and yield stress with increasing heat treatment temperature. Besides, it can be seen that uniform elongation increases at a heat treatment temperature of $400{ }^{\circ} \mathrm{C}$. For this reason, a heating temperature of $400{ }^{\circ} \mathrm{C}$ is selected for subsequent laser heat treatments operations.

To identify the time-dependent material properties of the alloy after short laser heat treatment with a maximum temperature of $400^{\circ} \mathrm{C}$, subsequent hardness measurements revealed to DIN 6506-1 were performed at defined time steps. In Fig. 3 the time-dependent, as well as the initial hardness distribution, is illustrated. It can be seen, that 15 min after the heat treatment the hardness is approximately $72.3 \mathrm{HB}$. The results show, that after a storage duration of $10 \mathrm{~h}$ at room temperature the hardness begins to increase. After 10 days the hardness reaches 108.2 HB. The reason for this is aging at room temperature. Therefore, the maximum storage time for components heat 
treated at $400{ }^{\circ} \mathrm{C}$ is $10 \mathrm{~h}$ before the softened areas solidify again.

\subsection{Temperature-dependent material properties of AA7075}

To identify the temperature-dependent material properties during the laser heat treatment, hot tensile tests were carried out by using the thermomechanical simulator type Gleeble 3500 according to DIN EN ISO 6892-2. The resulting flow curves as well as the temperature-dependent young's modulus are shown in Fig. 4 and are used for the simulations carried out in Sect. 3. The experimentally determined flow curves were approximated and extrapolated by using the law of Hocket-Sherby.

It can be seen that with increasing temperature, the material shows an enhanced ductile behavior. Despite this, the limiting temperature $\mathrm{T}_{\mathrm{G}}$ remains approximately comparable with increasing temperature, since the yield strength and the E-modulus are both decreasing (see formula 1). Using the determined material properties in the temperature range between room temperature and $400{ }^{\circ} \mathrm{C}$, it can be seen that the limit temperature for the aluminum alloy AA7075 is $\mathrm{T}_{\mathrm{G}}=342{ }^{\circ} \mathrm{C} \pm 26.5$.

The coefficient of thermal expansion of the alloy AA7075 was determined $0^{\circ}$ and $90^{\circ}$ to the rolling direction in a temperature range between $\mathrm{RT}$ and $400{ }^{\circ} \mathrm{C}$ using the optical $\mathrm{CCD}$ micrometer in combination with the thermomechanical simulator type Gleeble 3500. Figure 5 shows the coefficient of thermal expansion. It can be seen that alloy AA7075 has a thermal expansion coefficient of $\alpha_{\mathrm{th}, 0^{\circ}}=2.494 * 10^{-5} 1 / \mathrm{K}$ in the rolling direction. Perpendicular to the rolling direction, it is $\alpha_{\mathrm{th}, 90^{\circ}}=2.374 * 10^{-5} 1 / \mathrm{K}$. The reason for the slightly increased coefficient of expansion in the rolling direction may be the elongation of the grains during the cold rolling process.

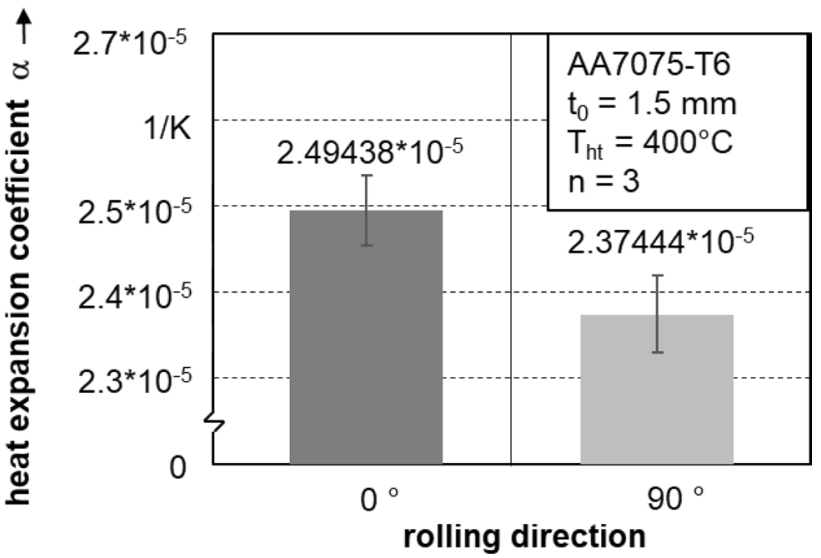

Fig. 5 Coefficient of thermal expansion for two rolling directions

\section{Numerical and experimental distortion behavior}

\subsection{Laser heat treatment}

In order to identify the distortion behavior as a function of different irradiation strategies, experimental as well as numerical irradiation operations with different irradiation strategies have been performed. The experimental tests are carried out using a diode laser of type Laserline LDM 3000100. For precise temperature control, a pyrometer is used to monitor and regulate the sheet temperature on the surface of the sheet facing the laser beam at the center of the laser spot with a scanning frequency of $50 \mathrm{~Hz}$. To verify the measured temperature, the heat distribution onto the aluminum sheets is measured additionally with the help of a FLIR SC7600 thermal camera. For the laser heat treatment and the subsequent distortion characterization, blanks were first locally heat treated as shown in Fig. 6 (left) and then optically measured (Fig. 6 right). The samples were measured with a GOM-ATOS system and then virtual measuring planes were inserted into the digitized components. This allows the
Fig. 4 Flow curves and the young's modulus of AA7075 at different temperatures

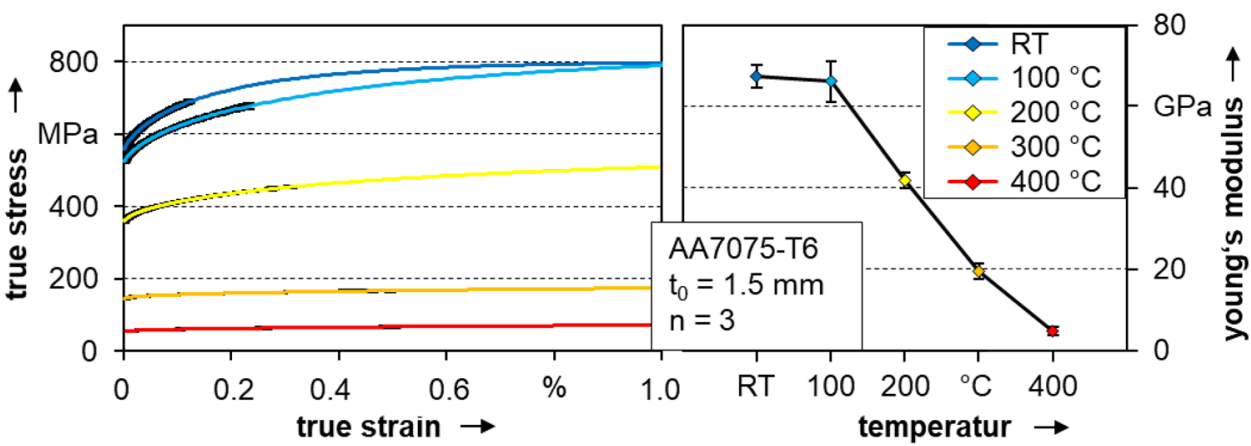


Fig. 6 Principle of laser heat treatment and subsequent distortion measurement on the specimens

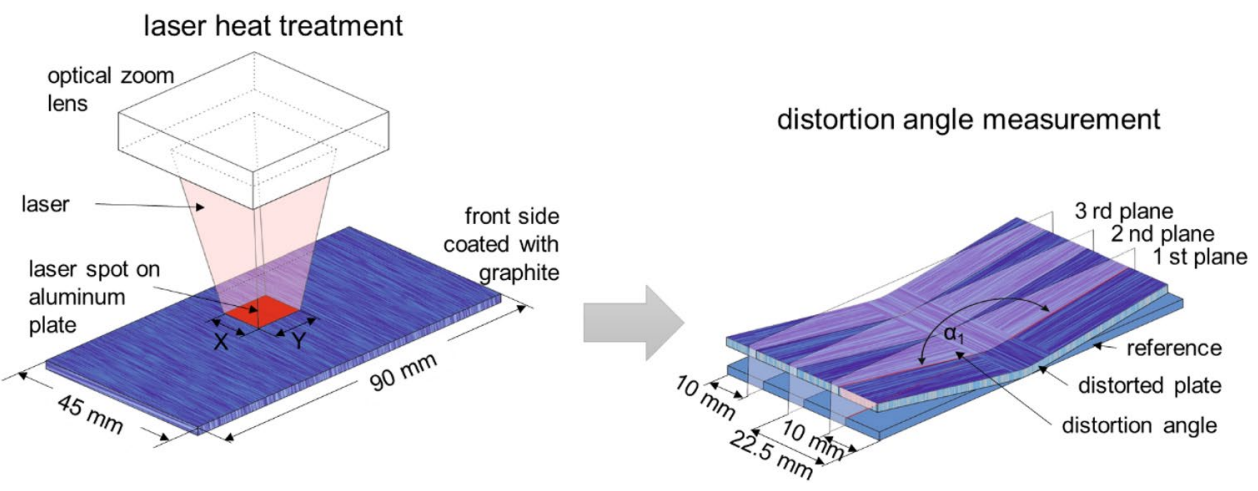

measurement of three distortion angles at different positions for each specimen.

With the help of the temperature-dependent material parameters determined in Sect. $2\left(\alpha_{\mathrm{th}}, \rho, \mathrm{s}_{0}, \mathrm{k}_{\mathrm{f}}, \mathrm{E}\right)$ and the extracted process parameters of the laser tests, the local heat treatment was simulated numerically with the software LS-Dyna. Reason for choosing the LS-Dyna software is the possibility of adjusting almost all parameters. For this purpose, the previously determined temperature-dependent flow curves (see Fig. 4), the average thermal expansion coefficient (see Fig. 5), and the output curves of the diode laser determined for the respective test parameters $\left(\mathrm{v}, \mathrm{A}, \mathrm{d}_{\mathrm{l}}\right)$ were used. The keyword FLUX_TRAJECTORY has been used to describe the thermal energy input. The element size of the used elements was set to $1 \mathrm{~mm}^{2}$ and a thickness of $0.2 \mathrm{~mm}$. To represent the thermal stresses, an implicit thermomechanically coupled solver was used to calculate the simulations. For a process-oriented simulation of the laser experiments, the laser power $\left(\mathrm{P}_{1}\right)$ outputs controlled by the pyrometer were derived and transferred to the simulation LS-Dyna. Because the material was not characterized concerning the residual stresses, it was not possible to take these into account for the numerical model. To ensure unrestricted thermal distortion of the simulated components, adapted bearing conditions were selected for the irradiation of the specimens.

\subsection{Distortion behavior}

To show the influence of different irradiation strategies and the accuracy of numerical irradiation on the resulting component distortion, both continuous and spotwise irradiation strategies were used. In previous investigations, it was already shown that the component distortion changes with varying irradiation temperatures [14]. For this reason, the experiments were conducted at a constant temperature $400{ }^{\circ} \mathrm{C}$. It is necessary to take into account that the residual stresses existing in the sheet material are not taken into account in the simulation when evaluating the results. First, the influence of different process parameters such as varying laser spot size $\left(\mathrm{d}_{1}\right)$ as well as different laser spot velocities (v) on the geometric component distortion was investigated. Figure 7 shows the numerical and experimental results of different linear irradiation strategies on the left and the results of spotwise heat treatment strategies on the right. The distortion angles shown have been measured
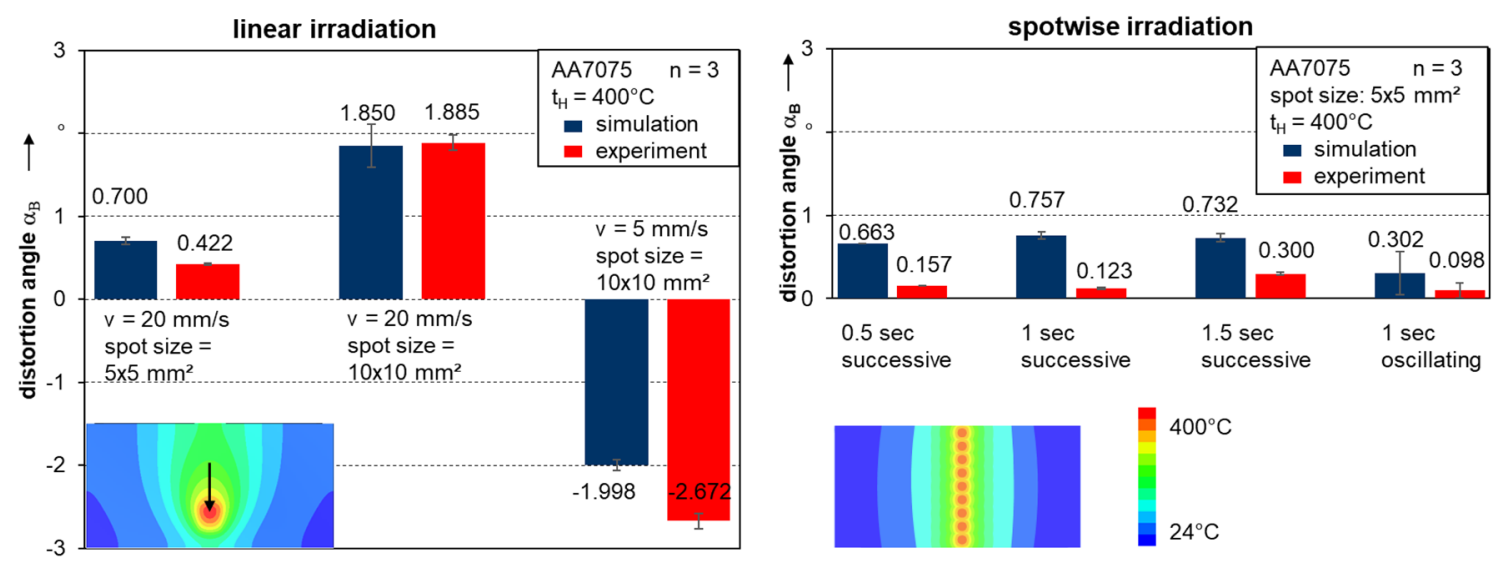

Fig. 7 Numerical and experimental distortion behavior of linear and spotwise irradiation 
on three reference planes each of the real and virtual components (see Sect. 3.1). In addition, five components each were experimentally heat treated and measured to provide statistical assurance. The results of the linear irradiation strategies show that the resulting component distortion can be reproduced both numerically and experimentally with a high correlation. It can be seen that an increasing laser spot size results in an increasing distortion angle $\left(\alpha_{\mathrm{B}}\right)$. This behavior is caused by the increased energy input as well as the larger impact area. Besides, it is also evident that both numerically and experimentally a negative component distortion occurs as soon as a traverse speed (v) of $5 \mathrm{~mm} / \mathrm{s}$ is set in combination with a laser spot geometry $\left(d_{1}\right)$ of $10 \times 10 \mathrm{~mm}^{2}$. The reason for the negative distortion behavior is the superposition of buckling mechanisms as well as the dissolution of residual stresses of the material. This is because with decreasing irradiation speed (v) and due to the high specific heat capacity $\left(c_{p}\right)$ of the material, a larger area is heated evenly and distortion mechanisms caused by temperature gradients have only a low influence.

Furthermore, the distortion behavior of spotwise heat treated components was simulated for different heat treatment durations and different irradiation strategies. The results of spotwise heat treatment show lower distortion angles compared to linear irradiation. In addition, a partially higher deviation between the experimental and numerical results can be seen in comparison. One reason for the high deviation may also be the unconsidered residual stress relaxation, which depends on previously applied deformations. For successive irradiated components, the variation of the heating time does not show a clear tendency concerning the bending angle $\left(\alpha_{\mathrm{B}}\right)$, both numerically and experimentally. In comparison, oscillating irradiation of the components both experimentally and numerically again shows a significant reduction of the resulting bending angle $\left(\alpha_{B}\right)$ by more than $58 \%$. One reason for the lower distortion angle may be the locally reduced energy input over time.

In summary, it can be seen that the distortion behavior and different distortion mechanisms of locally laser heat treated aluminum sheets can be reproduced numerically.
Currently, only linear irradiation strategies can be numerically simulated with high accuracy.

\section{Transfer of iraditaion strategies on a deep drawing geometry and evaluation}

The numerical and experimental laser heat treatment of the specimen geometry of Sect. 3 was carried out only on small component geometries (component surface $=4050.0 \mathrm{~mm}^{2}$ ) as well as locally limited heating areas. For this purpose, two heating strategies were transferred to larger components (component surface $=31,415.9 \mathrm{~mm}^{2}$ ). The geometries selected for this purpose are flat, rotationally symmetrical components with and without cutouts, which are used in sheet metal forming to determine the forming limit curve (FLC) on a laboratory scale in accordance to DIN EN ISO 12004-2 (Nakajima test). Since these investigations are focused on the influence of different irradiation strategies on the occurring component distortion as well aw the forming behavior and not on the characterization of the mechanical material properties in terms of elongation in percent at maximum force, only three of the specimens geometries were used for the experimental tests. For this purpose, the geometry for uniaxial tension (S50), plane strain (S100), and stretch (S245) have been selected.

The large-volume components were initially laser heat treated with the equipment described in Sect. 3.1. In order to ensure comparability to the results of Sect. 3.2, an oscillating spotwise and a linear heat treatment strategy was selected and applied to the component geometry. Table 1 shows the process parameters and the resulting total process times. It can be seen that linear irradiation takes only 5.5-6.8\% of the heat treatment time compared to spotwise heating. The reason for this is, on the one hand, the larger laser spot size of $30 \times 30 \mathrm{~mm}^{2}$ and, on the other hand, the continuous laser spot velocity of $10 \mathrm{~mm} / \mathrm{s}$. In addition, it has to be taken into mind that in the case of oscillating spotwise irradiation, the laser has to be switched on and off between each heat treatment position. This significantly increases the total irradiation time for spotwise irradiation.

Table 1 Irradiation parameters for big components

\begin{tabular}{|c|c|c|c|c|c|}
\hline & Spotsize $\left(\mathrm{mm}_{2}\right)$ & $\begin{array}{l}\text { Velocity of laserspoit (nun/s)/ } \\
\text { duration of inadiation (s) }\end{array}$ & $\begin{array}{l}\text { Temperatur } \\
\text { e }\left({ }^{\circ} \mathrm{C}\right)\end{array}$ & Resulting process time (s) & $\begin{array}{l}\text { Number inadiation } \\
\text { paths/inadiation } \\
\text { spots }\end{array}$ \\
\hline Linear inadiation & $30 \times 30$ & 10 nun/s & 400 & $\begin{array}{l}S 50=63 \mathrm{~s} \\
\mathrm{~S} 100=72 \mathrm{~s} \\
\mathrm{~S} 245=90 \mathrm{~s}\end{array}$ & $\begin{array}{l}5 \text { Paths } \\
6 \text { Paths } \\
6 \text { Paths }\end{array}$ \\
\hline Spotwise inadiation & $5 \times 5$ & $1 \mathrm{~s}$ & 400 & $\begin{array}{l}\mathrm{S} 50=922 \mathrm{~s} \\
\mathrm{~S} 100=1229 \mathrm{~s} \\
\mathrm{~S} 245=1641 \mathrm{~s}\end{array}$ & $\begin{array}{l}546 \text { Spots } \\
688 \text { Spots } \\
856 \text { Spots }\end{array}$ \\
\hline
\end{tabular}




\subsection{Temperature distribution of different radiation strategies}

To determine the influence of different irradiation strategies on the resulting temperature of the specimen surface, the FLIR SC7600 was used to record the temperature distributions onto the specimen surface at a recording frequency of $10 \mathrm{~Hz}$. To obtain a comparable measure from the thermal video afterward, an evaluation tool developed for this purpose was used to compress the video into a figure that illustrates the maximum temperature for each measuring position over the whole heat treatment operation and combines them into a maximum temperature distribution image. Figure 8 shows the temperature distributions of the different geometries using linear and spot wise irradiation strategies. Since the Nakajima specimens are deformed and characterized only in the center, only this zone was locally laser heat treated. It can be seen in Fig. 8 that a more homogeneous temperature distribution is achieved with the spotwise irradiation compared to the linear irradiation strategy. However, the aimed temperature of $400{ }^{\circ} \mathrm{C}$ is not reached with the spotwise irradiation. The reason for this is the high thermal conductivity of the material and the localized heating of the components. Besides, the evaluation shows that a cross-shaped pattern with insufficiently heated zones with a minimum temperature of $322{ }^{\circ} \mathrm{C}$ is recognizable at the heat treated specimens. Studies have already shown in the past that multiple irradiations of the same component area cause an increase in distortion angle [15], so no overlapping of the irradiation points was used to achieve a more homogeneous temperature distribution of the samples.

For linearly treated components, the maximum temperature of up to $456{ }^{\circ} \mathrm{C}$ indicates a significant temperature rise.
The reason for this is the temperature regulation with the help of the pyrometer. Since the pyrometer only records the temperature distribution in a circular area of $5 \mathrm{~mm}^{2}$ and the laser spot size is $30 \times 30 \mathrm{~mm}^{2}$, a overheating of the component is evident due to the delayed component heating behind the pyrometer.

\subsection{Geometrical accuracy of the heat treated component}

The heat treated parts were measured by using an optical measuring system type GOM-ATOS. Since it is not possible to measure the angles of the rotation-symmetrical components as in Sect. 3.2, the geometric deviation was determined by comparing the surfaces (height differences) with the reference components. In Fig. 9, the results of the geometrical difference measurement are visualized and the average and maximum geometrical deviations of the differently irradiated components are shown with the aid of frequency height deviations.

The geometric deviation for the spotwise irradiation strategy is significantly lower than for the linear irradiation strategy. One possible reason for this behavior may be the energy input distributed over a longer period. Additionally, as explained in Fig. 1, many of the distortion effects that occur are velocity-dependent. However, in the case of spotwise irradiation, the velocity of the laser spot is negligible. Besides, a small laser spot size was selected for point irradiation, which also has a positive effect on the distortion behavior of laser heat treated components. Taking a closer look at the surface comparisons, it is noticeable that in the case of spotwise irradiation, an area-related distortion is distributed over the entire component surface. With linear

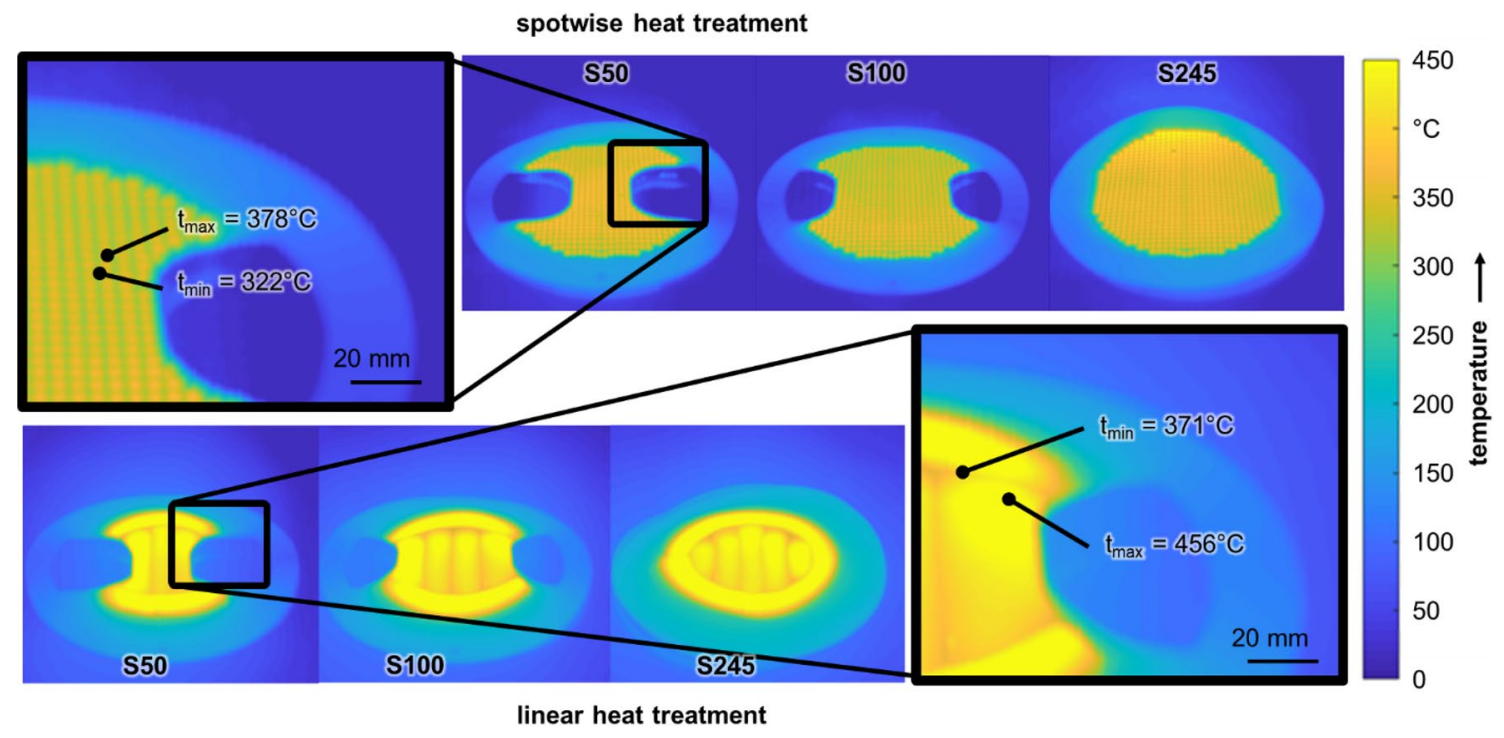

Fig. 8 Maximum temperature distribution at different radiation strategies 


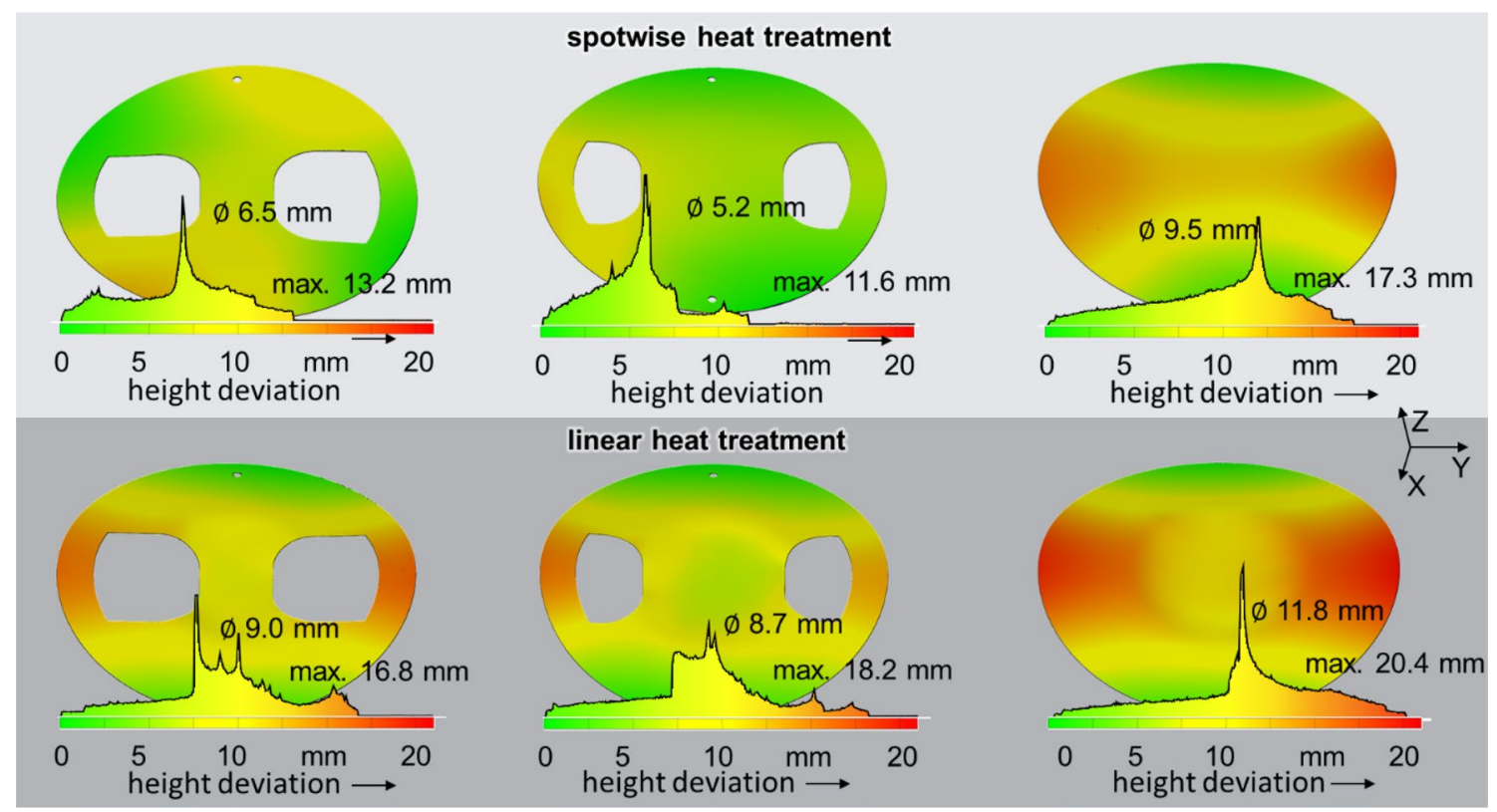

Fig. 9 Distortion behavior of large volume components

irradiation, in contrast, the height deviations are partially very unsteady. One possible reason for this distortion behavior of the spotwise heat treated components is the reduction of residual stresses (residual stress relaxation, see Sect. 1.1).

\subsection{Influence of the irradiation strategy on the failure behavior}

To investigate the influence of the different irradiation strategies on the forming and failure behavior, the heat treated and optically measured components were characterized within a maximum duration of $5 \mathrm{~h}$ to avoid aging in ambient conditions (see Sect. 2.1). During the Nakajima test, the component is stretched and an optical measurement system type Aramis is used to record the resulting strain distribution in the area of crack [16]. Subsequently, it is possible to calculate the major and minor strain as a function of the respective component geometry. In Fig. 10, the results of the strain measurement are illustrated. It can be seen clearly that the spotwise heat treated specimens shows the lowest strains. The linear irradiated sample also reveals lower strains than the material in its initial state but a significantly higher strain distribution than the spotwise heat treated components. A reason for this behavior is the uneven temperature distribution on the component surface for the selective heat treated components (see Sect. 4.1). The optical strain distribution on the Nakajima specimens tested also revealed a heterogeneous strain distribution on the spotwise heat treated specimen surfaces.

With the help of the determined machine data, the maximum necessary punch forces and the resulting maximum

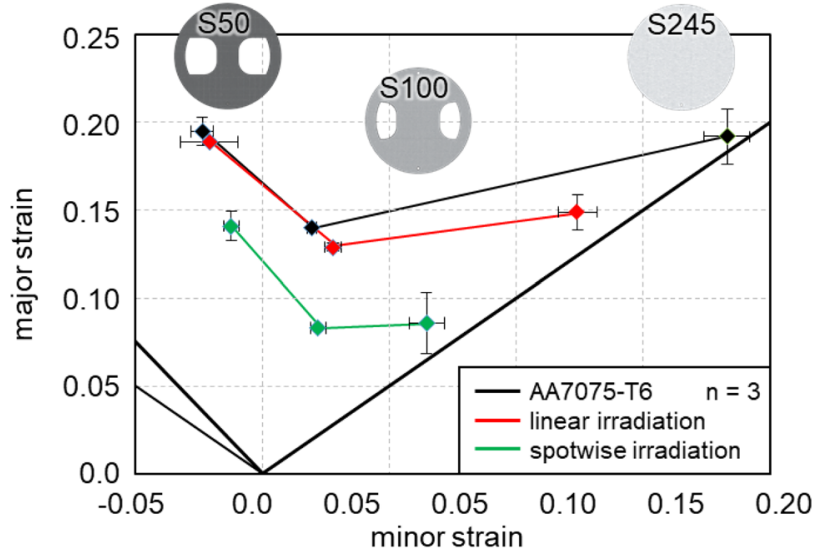

Fig. 10 FLD of the alloy AA7075 after different heat treatment strategies

dome heights have been determined as shown in Fig. 11. Regarding the maximum dome height, different behavior can be seen for the varying types of loads of the specimens depending on the respective irradiation strategy. The spotwise heat treated specimens achieve equally high drawing depths for the plane strain as well as in the tensile strain load. However, the maximum draw depth for the biaxial stress $(20.4 \mathrm{~mm})$ is over $17 \%$ reduced compared to the initial T6 condition $(24.7 \mathrm{~mm})$. One reason for the smaller drawing depth may be the cross-shaped cold zones of the specimens resulting from the spotwise heat treatment. In these areas, the specimen has not received the necessary temperature to soften the material sufficiently (described in Sect. 4.1). As a result, this pattern has the effect of initiating cracks due to 


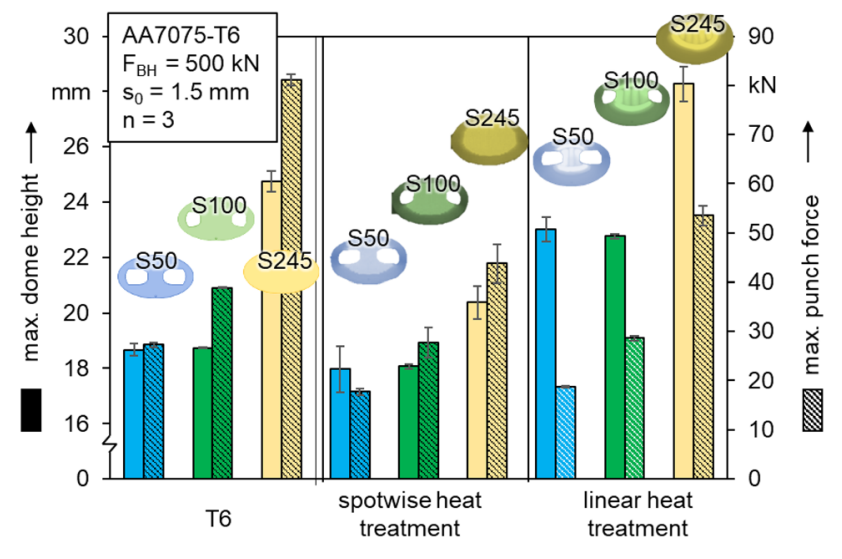

Fig. 11 Maximal punch force and dome height for the FLC

the limited forming behavior in these areas. For this reason, the maximum punch forces of the spotwise specimens are also lower than for the initial state. For the linearly irradiated components, higher maximum dome heights and lower maximum punch forces are evident for all load conditions. Thus, a sufficient softening of the test material can be assumed for the linear irradiation strategy.

\section{Conclusion}

Regarding the experimental and numerical results as well as the performed characterization tests, the following conclusions can be given for the laser-assisted short-time heat treatment:

- The linear irradiation strategy enables faster component heating than spotwise heat treatment. However, the linear strategy results in higher distortion than the localized method.

- A significant reduction of the distortion is ensured by using spotwise irradiation strategies for heat treatment.

- Selective irradiation leads to lower maximum temperatures compared to linear irradiation. Consequently, crossshaped component areas that are not sufficiently heated occur.

- Forming tests show that local heat treatment causes a reduction in the necessary maximum punch forces. However, increased drawing depths are only achieved with the linear irradiation strategy. The reason for this in case of spotwise irradiation are the insufficiently heated component areas, which have a crack-initiating effect as discussed in Sect. 4.1 and 4.3.

In future investigations, the simulation of residual stresses introduced into the material in advance will be taken into account. In this way, increased accuracy of numerical and experimental irradiation processes is expected. Furthermore, the adaption of spotwise heat treatment strategies is required to achieve better formability.

Acknowledgements The authors would like to thank the German Research Foundation (DFG) for supporting the present investigations which were performed within the scope of the research project "Laser assisted strategies for the manufacturing of property-enhanced Tailor Heat Treated Blanks (DFG ME 2043/65-1)',. The authors would also like to thank the student Miriam Eichinger for her support.

Funding Open Access funding enabled and organized by Projekt DEAL.

Open Access This article is licensed under a Creative Commons Attribution 4.0 International License, which permits use, sharing, adaptation, distribution and reproduction in any medium or format, as long as you give appropriate credit to the original author(s) and the source, provide a link to the Creative Commons licence, and indicate if changes were made. The images or other third party material in this article are included in the article's Creative Commons licence, unless indicated otherwise in a credit line to the material. If material is not included in the article's Creative Commons licence and your intended use is not permitted by statutory regulation or exceeds the permitted use, you will need to obtain permission directly from the copyright holder. To view a copy of this licence, visit http://creativecommons.org/licenses/by/4.0/.

\section{References}

1. Siebel E, Beisswänger H (1953) Ziehversuche Mit Hartgewaltzen Und Partiell Geglühten Ronden Zur Erhöhung Des Ziehverhältnisses. Mitteilung Aus Der Staatlichen Materialprüfanstalt An Der Technischen Hochschue Stuttgart 7:89-93

2. Graser M, Fröck H, Lechner M, Reich M, Kessler O, Merklein M (2016) Influence of short-term heat treatment on the microstructure and mechanical properties of En Aw-6060 T4 extrusion profiles-part B. Prod Eng Res Dev. https://doi.org/10.1007/S11740-016-0684-5

3. Hofmann A (2001) Deep drawing of process optimized blanks. J Mater Process Technol. https://doi.org/10.1016/S0924 -0136(01)00948-7

4. Geiger M, Merklein M, Vogt U (2009) Aluminum tailored heat treated blanks. Prod Eng Res Dev. https://doi.org/10.1007/S1174 0-009-0179-8

5. Uwe Vogt Seriennahe Auslegung Von Aluminium Tailored Heat Treated Blanks. Dissertation, Bamberg

6. Bianco N, Manca O, Nardini S, Tamburino S (2009) Transient heat conduction in solids irradiated by a moving heat source. Ddf. https ://doi.org/10.4028/Www.Scientific.Net/Ddf.283-286.358

7. Vollertsen F, Geiger M (1996) Laserstrahlumformen. Lasergestützte Formgebung, Meisenbach

8. Kahrimanidis A, Wortberg D, Merklein M (2015) Approach to minimize the distortion of 6xxx-aluminum tailor heat treated blanks in industrial applications. Prod Eng Res Dev. https://doi.org/10.1007/ S11740-015-0628-5

9. Holzer S (2020) Berührungslose Formgebung Mit Laserstrahlung. Dissertation, Bamberg

10. Simson T, Emmel A, Dwars A, Böhm J (2017) Residual stress measurements on aisi 3161 samples manufactured by selective laser melting. Addit Manuf. https://doi.org/10.1016/J.Addma.2017.07.007

11. Shi Y, Liu Y, Yi P, Hu J (2012) Effect of different heating methods on deformation of metal plate under upsetting mechanism in laser forming. Opt Laser Technol. https://doi.org/10.1016/J.Optla stec.2011.08.019 
12. Magee J, Kg W, Wm S (1998) Advances in laser forming. J Laser Appl. https://doi.org/10.2351/1.521859

13. Vollertsen F (1994) An analytical model for laser bending. Lasers Eng 2:261-276

14. Hoseinpour Gollo M, Sm M, Moslemi Naeini H (2011) Statistical analysis of parameter effects on bending angle in laser forming process by pulsed nd: yag laser. Opt Laser Technol. https://doi. org/10.1016/J.Optlastec.2010.07.004

15. Poprawe R (2005) Lasertechnik Für Die Fertigung. Springer, Berlin
16. Dilmec M, Hs H, Ozturk F, Turkoz M (2013) Detailed investigation of forming limit determination standards for aluminum alloys. J Test Eval. https://doi.org/10.1520/Jte104356

Publisher's Note Springer Nature remains neutral with regard to jurisdictional claims in published maps and institutional affiliations. 